\title{
Optimizing Oil Production from the Troll Field
}

\author{
* Boee O., ** Nerby G., * Wennemo S. E. \\ * Norsk Hydro a. s., Norway \\ ** Loke a. S., Norway
}

\begin{abstract}
Copyright 1995, Steering Committee of the European IOR - Symposium.
This paper wos presented at the 8th. European IOR - Symposium in Vienns, Austria, May 15 - 17, 1995

This paper was selected for presentation by the Steering Committee, following review of information contained in an abstract

submitted by the author(s). The paper, as presented has not been reviewed by the Steering Committee.
\end{abstract}

\begin{abstract}
The giant Troll gas field offshore Norway also contains one of the largest oil accumulations in the North Sea. The oil is located in thin layers sandwiched between the gas cap and an active aquifer. Its development is based on long, horizontal wells tied back to a concrete semi-submersible production platform. The oil will be developed stagewise with first oil planned in late 1995.

A successful development relies on optimal well locations and production/injection strategy. Drilling of very long horizontal sections has the advantage of increased drainage area pr. well. However, the potential is limited due to wellbore friction which may reduce the effective length of a well.

The wells are drilled as satellite wells tied back to subsea manifold stations. Two gathering lines transport the fluids from the manifold to the riser base of the platform. Each well can be connected to the one or the other gathering line by operating valves on the manifold. This flexibility is modelled by a network module that interacts with the reservoir simulator.
\end{abstract}

\section{Introduction}

The complexity of Troll together with simultaneous oil and gas production from various parts of the field, makes reservoir development planning and well and reservoir management a great challenge.
Well locations and production strategy are discussed in Section 2.2. To obtain economic oil production, the wells will be completed in the lower part of the oil rim close to the oil-water contact. The high water production which is expected can, to some extent, be controlled by gas injection. A flexible gas injection scheme is therefore implemented.

Section 2.3 is concerned with the lengths of the horizontal producers. The planned length of the wells on Troll has been increased from $800 \mathrm{~m}$ in the 1991 field development plan to $1500 \mathrm{~m}$ today. However, well bore friction may reduce the effective length of a well. The effect of increased well length has been analysed based on measured pressure drawdown and inflow profile for a $1350 \mathrm{~m}$ long predrilled well.

The fluid transportation system is discussed in Section 2.4 and 2.5. Two gathering lines will be installed from each manifold to the platform. At any time, each well has the freedom to connect to one of the two lines. The problem of finding the optimal distribution of wells on the two lines as a function of time is defined as dynamic well routing.

Due to the thin oil layers on Troll, gas and water coning become very important. These effects dictate the capacity in the gathering lines. The well rates must therefore be controlled to optimise the capacity.

To solve these problems, a network module that interacts with the simulator has been developed. The module is described in Section 3. Examples are presented in Section 4. 


\section{Reservoir Management}

\subsection{Background}

The Troll oil and gas field, discovered in 1979, is located in $300 \mathrm{~m}$ water depth offshore Norway and covers an area of $700 \mathrm{~km}^{2}$ (Fig. 1). Depth to top reservoir varies between $1300-1500 \mathrm{~m}$ MSL. The field consists of three easterly tilted fault compartments (Fig. 2). In the westernmost compartment, the Troll West Oil Province (TWOP), the oil column is $22-27 \mathrm{~m}$ thick. The estimated hydrocarbons in-place are $155 \times 10^{6} \mathrm{Sm}^{3}$ of oil and $27 \times 10^{9} \mathrm{Sm}^{3}$ of gas. In the central fault block, the Troll West Gas Province (TWGP), the oil column is $12-14 \mathrm{~m}$ thick and the estimated in-place volumes are $440 \times 10^{6}$ $\mathrm{Sm}^{3}$ of oil and $570 \times 10^{9} \mathrm{Sm}^{3}$ of gas. The major gas accumulation is found in Troll East with a gas inplace estimated at $1072 \times 10^{9} \mathrm{Sm}^{3}$.

The development of Troll is divided in three phases. Phase 1 is production of the gas resources in Troll East, planned to commence in 1996 from a gravity based concrete platform (Troll A). Phase 2 covers the development of the oil resources in Troll West, and is planned to commence late 1995. Due to the shallow reservoir and the spread of the oil over a large area, the oil will be produced by subsea wells with the wellstreams routed to process facilities on a semi-submersible concrete platform (Troll B). Phase 3 includes large scale gas production from Troll West, and no decisions on development have been taken to date.

The 18 oil wells planned in the TWOP will be tied back to four subsea manifold stations. The fluids are transported to the Troll B platform by two parallel gathering lines per manifold station.

It is flexibility on the Troll B platform to accommodate up to five TWGP oil production clusters. So far it is decided to develop one cluster with $4-6$ wells and with production start-up early 1996. Further development of the thin oil zone, which contains the majority of the oil resources on Troll, will be taken subsequent to production experience from the first cluster.

The oil production potential on Troll was confirmed by long-term testing in 1990-91.1,2 The two long-term tests increased the understanding of producing from thin oil zones and have reduced the uncertainty associated with the field development.

\subsection{Optimised well locations and production strategy}

Economic oil production from the thin oil zones on Troll requires the use of horizontal wells. It is estimated that one horizontal well of length 500 $800 \mathrm{~m}$ can replace up to four vertical wells.

Oil production profiles for wells on Troll are characterised by a high initial rate and an early decline caused by gas and water influx. The ideal depth of a horizontal section is close to the oilwater contact (OWC) provided a low permeable sand is present below the OWC to slow down the inflow of water. Such conditions are found several places in the TWOP and are estimated to give oil recoveries for the best wells up to $7 \times 10^{6} \mathrm{Sm}^{3}$.

Because target locations of the horizontal sections are close to the OWC, water invades the well after short time while gas breakthrough may be delayed up to one year after production start. When gas breakthrough occurs, the strategy for most wells is to reduce the liquid rate by the subsea choke until the gas cone retires. This procedure has to be repeated several times during the production period and a nearly continuous decline of the well rate results.

A steadily increasing water cut combined. with a decline in the reservoir pressure causes the tubing head pressure of a well to drop, and the well may shut in when the pressure is too low to transport the fluids to the platform. Simulation studies have indicated that the oil recovery from the TWOP may be improved by partly reinjection of associated gas. Gas injection reduces the inflow of the aquifer and enables most wells, especially wells at the flank of the reservoir, to produce for a longer period.

Wells which have moderate water cuts are estimated to be negatively affected by gas injection . This is because the gas-oil contact (GOC) is pushed downwards and the critical liquid rate to gas coning is reduced. The gas injection strategy will be optimised during production. The development concept has flexibility to either reinject the gas or to export it via the Troll A facilities.

\subsection{Optimised well lengths}

In the plan for development and operation (PDO) submitted in 1991, $800 \mathrm{~m}$ horizontal sections were assumed. Recent years technological advances have qualified longer wells, and the target length for wells on Troll has been increased to approximately $1500 \mathrm{~m}$. At present (March-95) four of the eight planned predrilled wells have been finished. These wells have been drilled and completed with horizontal lengths of $1350-1500 \mathrm{~m}$. Pre-packed screens have been installed in the horizontal sections to avoid sand production.

Three of the wells have been production tested to date. It has been demonstrated for two of the 
wells that oil is flowing into the entire horizontal section. The third well is flowing only from the first $750 \mathrm{~m}$ due to incomplete clean-up. This well will be re-entered prior to production start.

The very good reservoir properties on Troll give productivity indices for the wells up to 8000 $\mathrm{Sm}^{3} / \mathrm{d} / \mathrm{bar}$. The resulting low pressure drop from the reservoir into the well is of the same magnitude as the pressure drop due to friction in the liner. Since the friction pressure loss becomes larger towards the heel of the well, a non-linear inflow to the well results.

The measured inflow profile and pressure drawdown for the $1350 \mathrm{~m}$ long well $31 / 2-\mathrm{G}-4 \mathrm{AH}$ are shown in Fig. 3. Although part of the flow which apparently enters the heel end of the well, most probably is caused by annular flow outside the liner, the non-linear nature of the inflow is clearly demonstrated.

The pressure drop in the heel of a well due to friction, tends to increase with increased length of the well. It is therefore a limit for which a further increase of the length of the horizontal section will not be economical. Since the measured inflow profile for well $31 / 2-G-4 A H$ shows a relatively low inflow in the toe, the question was raised whether it was economical to drill this well as longs as $1350 \mathrm{~m}$.

The situation has been analysed as follows:

- Firstly, the measured initial inflow profile for the $1350 \mathrm{~m}$ long well was matched in the full field reservoir simulation model, confer Fig. 3

- Then, a long term prediction of the production potential for the $1350 \mathrm{~m}$ long well was made.

- Similarly, a long term prediction was made for a fictitious $800 \mathrm{~m}$ long well in the same area and with the same reservoir parameters as resulting from the matching process.

The resulting production profiles are shown in Fig. 4. The total oil volume produced by the well is seen to be reduced by $20 \%\left(1 \times 10^{6} \mathrm{Sm}^{3}\right)$ when the length is reduced from $1350 \mathrm{~m}$ to $800 \mathrm{~m}$. Although some of the neighbour wells in the reservoir are able to recover part of the oil lost by shortening the well, the benefit of drilling a $1350 \mathrm{~m}$ long well is clearly demonstrated.

The drilling of longer wells than $1500 \mathrm{~m}$ on Troll is being considered. The success of such wells depends on the presence of a large drainage area, with good geological control. Furthermore, a restrictive target tolerance box must be applied while drilling the horizontal section to be able to push the liner into the toe of the well. The maximum allowed vertical deviation is $\pm 1 \mathrm{~m}$.

\subsection{Fluid transportation system}

The subsea horizontal wells on Troll are drilled as satellite wells tied back to subsea manifold stations. Each manifold station will accommodate from four to eight wells. The satellite wellheads are placed close to the manifold, usually at distances less than $200 \mathrm{~m}$, and are connected to the manifold by 8 inches lines. Two 10 inches gathering lines will transport the fluids from each manifold station to the riser base of the platform. In the TWOP the length of the gathering lines varies between 4 and $10 \mathrm{~km}$. At any time, each well can be connected to the one or the other gathering line by operating valves on the manifold.

Oil wells on Troll are expected to show large individual variations with respect to gas and water coning. This is primarily due to local variation in reservoir properties, but also the location of the well relative to the side aquifers is important. Generally, oil production from wells at the edge of the reservoir is limited by a high water cut while interior wells are limited by the critical rate to gas coning. Typical well production profiles and performance plots are shown in Figs. 5 and 6.

The subsea production system and some typical performance data are shown in Fig. 7. A schematic illustration of the manifolding system including the flexibility in the routing, is shown in Fig. 8.

\subsection{Dynamic well routing}

As stated in the previous section, each well has the freedom to connect to one (of the two) gathering lines. The problem of finding the optimal distribution of the wells on the two lines as a function of time is defined as dynamic well routing.

Consider a manifold with $\mathrm{n}$ wells. The number of possible well routing combinations is $2^{n-1}-1$. For example, for a three-well manifold $(n=3)$ the number of combinations is three. In this case, two of the wells can be connected to one of the lines, and the third well to the second, making a total number of three combinations. In the Troll oil development, the number of wells sharing a common manifold will be between four and eight. The wells sharing a gathering line must have a common manifold pressure (i.e. the pressure at the point where the well flows meet). Subsea chokes make it possible to choke each well individually. The manifold pressure and consequently also the transport capacity will be dictated by the well with 
the lowest well head pressure. The other wells connected to the gathering line, will have to be chóked back.

\section{The network module}

\subsection{Modelling of networks}

Most commercial simulators are not equipped with network modelling facilities. To our knowledge, dynamic well routing is not covered. Reservoir simulation on Troll up to 1993 was based on a simplified representation of the subsea network and the transportation capacity. The capacity was pre-calculated based on well performance characteristics typical for the early, intermediate and late production period and passed to the simulator as an upper limitation. At the same time, a minimum wellhead pressure constraint was applied for individual wells. This approach resulted in a fairly realistic production profile in total, but part of the profile could be erroneous in positive or negative direction. Only a tedious iteration process could ensure a realistic profile at all times. On this background, the development of a network module based on dynamic well routing was started. The work was performed during 1993 and the module was implemented into the reservoir simulator.

Simultaneous modelling of the reservoir and flow in well and pipeline networks is a difficult problem to handle. The different time scales between reservoir and pipeline flow and the compatibility conditions necessary for matching flow in the reservoir and in the network, are the main reasons for this. For simultaneous modelling, the complexities seem to grow with the degree of implicitness of the coupling between the network module and the simulator. For a discussion of these topics we refer to the paper by Schiozer and $\mathrm{Aziz}^{3}$.

For our application, a simple explicit coupling has been both powerful and satisfactory:

1 The well rates and pressures at timelevel $\mathbf{n}$ are passed on to the network module.

2 The network module decides on new well rates and control data for timelevel $n+1$.

3 The simulator precedes to timelevel $n+1$. Fig. 9.

\subsection{Input data}

The network module requires the following input data:

Static data

- Definition of wells and clusters (the network itself).

- Definition of all possible well routing combinations.

- Parameters controlling riser base gas lift.

- Constraints on maximum choking and control margins.

- Flow performance tables for the gathering lines.

\section{Dynamic data}

- Liquid rate, water cut, gas-oil ratio and tubing head pressure for each well.

- Control mode for each well (individual control or group control).

\subsection{Definition of capacity}

The capacity is estimated by use of flow performance tables for the gathering lines. Such tables give a correlation between two pressures and three flow variables. Consider a subsea manifold with two gathering lines $l, l=1,2$. Let the three flow variables be water cut $\mathrm{WCT}_{l}$, gas-oil ratio $\mathrm{GOR}_{l}$, and liquid rate $Q_{l}$. The two pressures will be the manifold pressure $P_{l}^{m}$ and the inlet platform pressure $P_{s}$. The functional relationship is

$$
F\left(Q_{l}, \mathrm{WCT}_{l}, \mathrm{GOR}_{l}, P_{l}^{m}, P_{s}\right) \text {. }
$$

Given a routing combination, the gathering line liquid rate, water cut and gas-oil ratio can be calculated. The manifold pressure $P_{l}^{m}$ for a gathering line is defined as the minimum of the well head pressures $p_{l}^{i}, i=1,2, \ldots, n_{l}$, where $n_{l}$ is the number of wells connected to the line:

$$
P_{l}^{m}=\min _{i=1,2 \cdots n_{l}} p_{l}^{i} .
$$

According to Eq. (2), it is assumed that at least one of the wells connected to the gathering line will produce against the manifold pressure (open choke). Optionally, a control margin may be 
defined. This margin is represented as a constant added to the right hand side of Eq. (2)

The gathering line capacity $Q_{l}^{c}$ is defined as the maximum amount of liquid that can be transported through the gathering line given the water cut, the gas-oil ratio, the manifold pressure, and the inlet platform pressure (separator pressure). The difference between the capacity and the liquid delivered (i.e. simulated) is denoted as the additional capacity $\Delta Q_{l}^{a}$ :

$$
\Delta Q_{l}^{a}=Q_{l}^{c}-\Sigma_{i=1}^{n_{l}} q_{l}^{i} \text {. }
$$

If the above quantity is negative, there is a lack of capacity.

The network module contains an option for considering gas lift at the riser base. If gas lift is needed, fixed amounts will be supplied in steps until one of the following criteria is met:

- The improvement in capacity does not pay off.

- The required amount of lift gas is not available.

- There is additional capacity.

$\circ$

\subsection{Optimal well routing}

The optimal well routing is defined as the routing combination which maximise

$$
\min \left\{\Delta Q_{1}^{a} \Delta Q_{2}^{a}\right\} \text {. }
$$

According to the above expression, the combinations are ranked by considering the minimum additional capacity for both lines. This principle is important. If the combinations were ranked after the manifold additional capacity $\Delta Q_{1}^{a}+\Delta Q_{2}^{a}$, a routing with negative additional capacin for one of the lines could be optimal. At the same time, another combination with positive additional capacities for both lines could exist. Therefore, a combination with positive additional capacities for both lines is preferred.

\subsection{New well rates}

The new rates for the wells sharing a gathering line are based on the additional capacity for the line. By default, the rates are increased or decreased by an equal factor. It is also possible to prioritise between wells. For instance, low water cut wells can be prioritised when there is additional capacity, and the rate of high water cut wells can be reduced more heavily compared to other wells if there is a lack of capacity.
The manifold water cut, gas-oil ratio and pressure will in general change as the liquid rate varies. The explicit capacity calculated by the network module is therefore only an approximation for the next timestep. However, it can be taken as an indication to whether the rates should be increased or decreased. In the present version of the program, the new rates are adjusted to make up for half of the additional capacity. Large oscillations in capacity between timesteps can result if the well rates are changed more than this.

The explicit method does not guarantee that there is sufficient capacity available at each timestep. This can occur if there are large changes in rates and pressures from one timestep to the next, such as when gas or water breakthrough occur, or when wells are opened. However, for most cases the method gives satisfactory results.

\subsection{Rules for advising new rates to simulator}

Logic for advising new rates to the simulator has been constructed. At present, the network module has been interfaced with the reservoir simulator Eclipse $^{4}$.

In Eclipse, wells can be on individual well control (operating at a well target) or on group control (the well is producing its' share of a group target).

The well rates suggested by the network module will not overwrite any constraints on rates, pressures, gas-oil ratios or water cuts specified in the simulator input file. If the network module recommends a higher liquid rate for a well than the maximum allowed, the well will produce at the maximum rate. We also note that if there is additional capacity, well rates will not be increased if the wells are operating on group control. Therefore, if possible, a group level rate target is respected. However, if the wells are on group control, and there is a lack of capacity, the well rates will be reduced.

\section{Examples}

Liquid production profiles for one of the clusters are shown in Figs. 10 and 11 . A simulation without the network module (Fig. 10) is compared to a simulation with the module included (Fig.11). The simulation done without the module leads to unrealistically high liquid production (reservoir delivery) compared to the amount possible to transport. With the module included, the two curves are nearly identical. Since the liquid rates are adjusted (reduced) in the latter case, the lifetime of the cluster is extended. 
Fig. 12 shows the oil production profiles for a high water cut well. The oil rate is steadily decreasing for thê first years, until gas breakthrough improves lift and production elsewhere in the reservoir reduces the water cut. Without the network module, the oil production becomes too optimistic.

Wells in the TWGP are planned to produce free gas in addition to oil (super-critical production). A TWGP cluster will therefore produce against a gas target rate. Due to a steadily increased water cut, this plateau rate may not be maintained in the last part of the production period. Fig. 13 shows that the predicted gas production profile may become too optimistic if the simulation is run without the network module.

\section{Conclusions}

- Successful development of the thin oil rim in the Troll Field depends on long horizontal wells in optimal locations relative to the fluid contacts. Present plans are based on approximately $1500 \mathrm{~m}$ long wells, but there is potential for increasing the well length up to $2000 \mathrm{~m}$ under certain conditions.

- The most powerful tool for reservoir management on Troll is the flexible gas injection scheme which gives opportunity to control the inflow of the aquifer to some extent.

- Flow in the production network has been successfully modelled by a purpose-built network module which interacts with the reservoir simulator. The method has lead to realistic production profiles within the required degree of accuracy.

\section{Acknowledgements}

The authors wish to express their thanks to all their colleagues in Norsk Hydro Exploration and Production Division who have contributed to this paper and to the management of Norsk Hydro a.s for permission to publish it. We also thank the other Troll licence owners for permission to publish this paper. The opinions expressed are those of Norsk Hydro a.s, and may not represent the views of other partners.

\section{Nomenclature}

GOR I Gas-oil ratio, gathering line no. 1

$Q_{l} \quad$ Liquid rate, gathering line no. 1

$Q_{l}^{c} \quad$ Capacity, gathering line no. 1

$q_{l}^{i} \quad$ Liquid rate, well no. $\mathrm{i}$ connected to gathering line no. 1

$\Delta Q_{l}^{a} \quad$ Additional liquid capacity, gathering line no. 1

$p_{l}^{i} \quad$ Well head pressure, well no. $\mathrm{i}$ connected to gathering line no. 1

$P_{l}^{m} \quad$ Manifold pressure, gathering line no. $\mathrm{i}$

$\mathrm{WCT}_{l}$ Water cut, gathering line no. 1

\section{References}

1. Lien, S.C., Seines K., Havig S.O. and Kydland,T.: "The First Long-Term Horizontal-Well Test in the Troll Thin Oil zone", JPT, August 1991, p. 914.

2. Haug, B.T.: "The Second Long-Term Horizontal Well Test in Troll: Successful Production from a $13 \mathrm{~m}$ Oil Column With the Well Partly Completed in the Water Zone", paper SPE 24943 presented at the 67th SPE Annual Technical Conference and Exhibition, Washington DC, October 4-7, 1992.

3. Schiozer D.J. and Aziz K.: "Use of Domain Decomposition for Simultaneous Simulation of Reservoir and Surface Facilities", paper SPE 27876 presented at the Western Regional Meeting, Long Beach, March 23-35, 1994.

4. Eclipse Manual Set Version 94A, Intera Information Technologies Limited, England. 


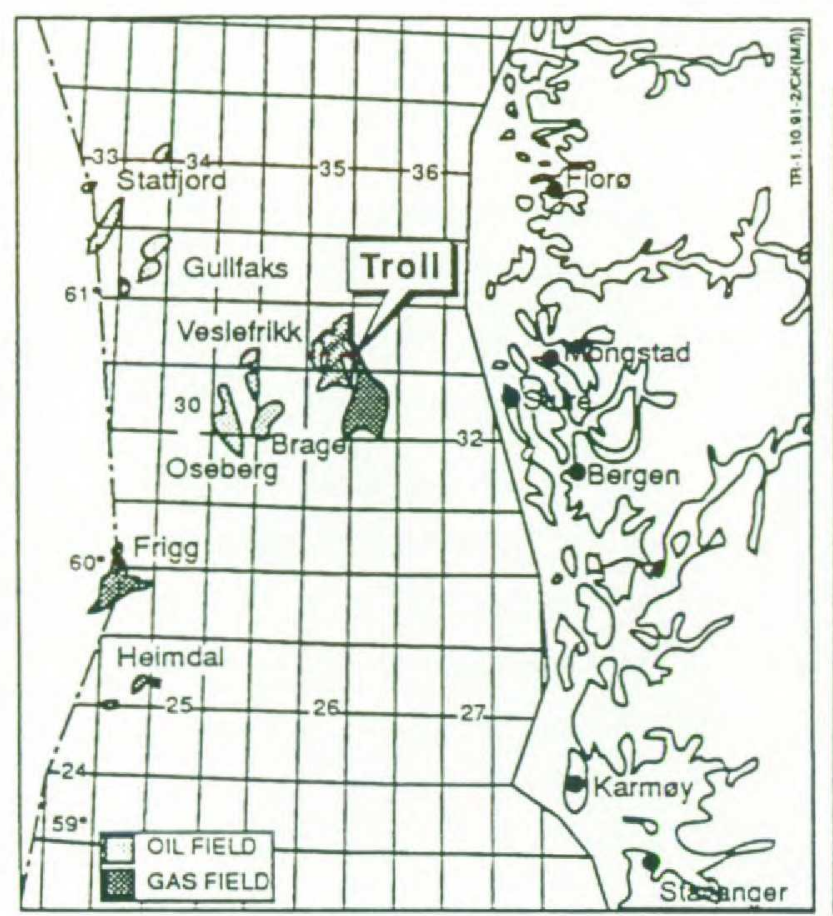

Fig. 1. Troll field location map

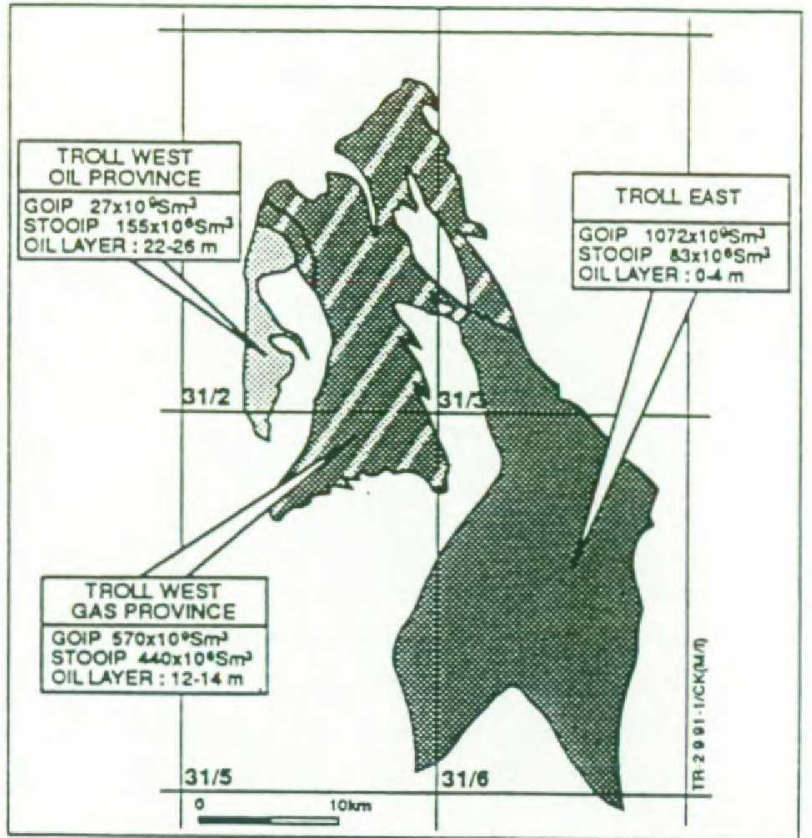

Fig. 2. Troll field hydrocarbons in place

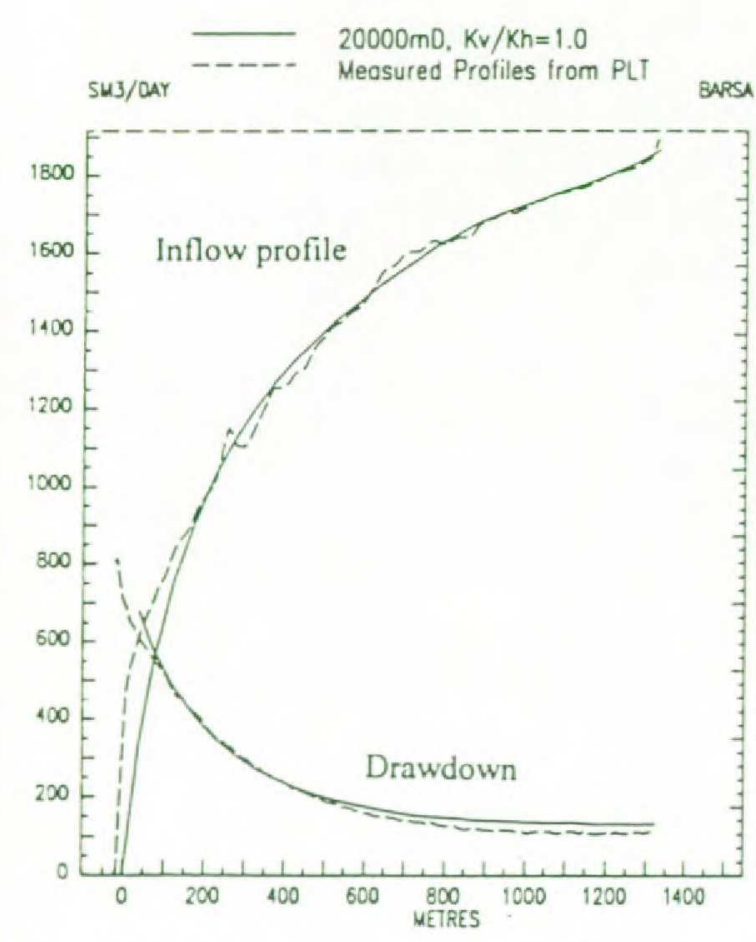

Fig. 3. Inflow profile along well $31 / 2-G-4 H$

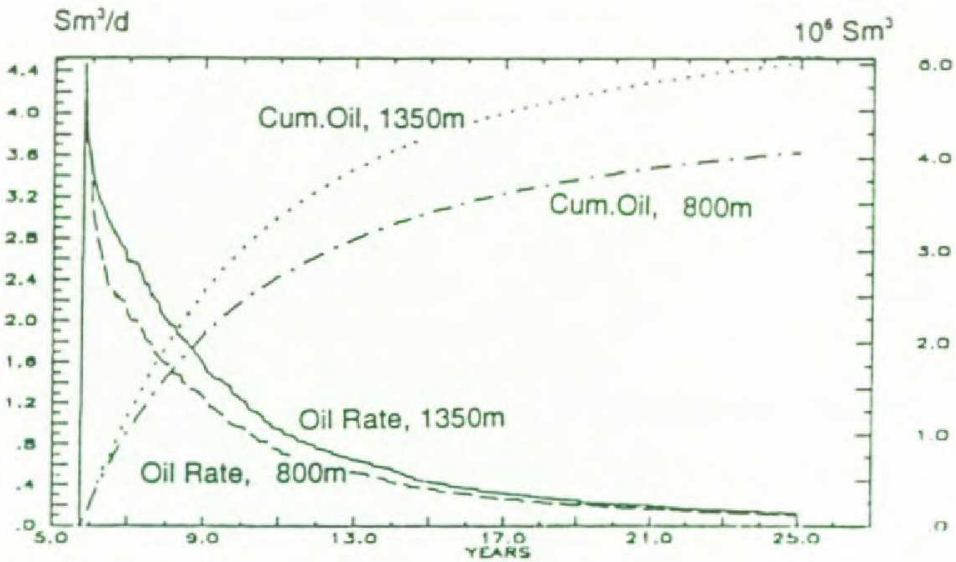

Fig. 4. Comparison between $800 \mathrm{~m}$ and $1350 \mathrm{~m}$ well 


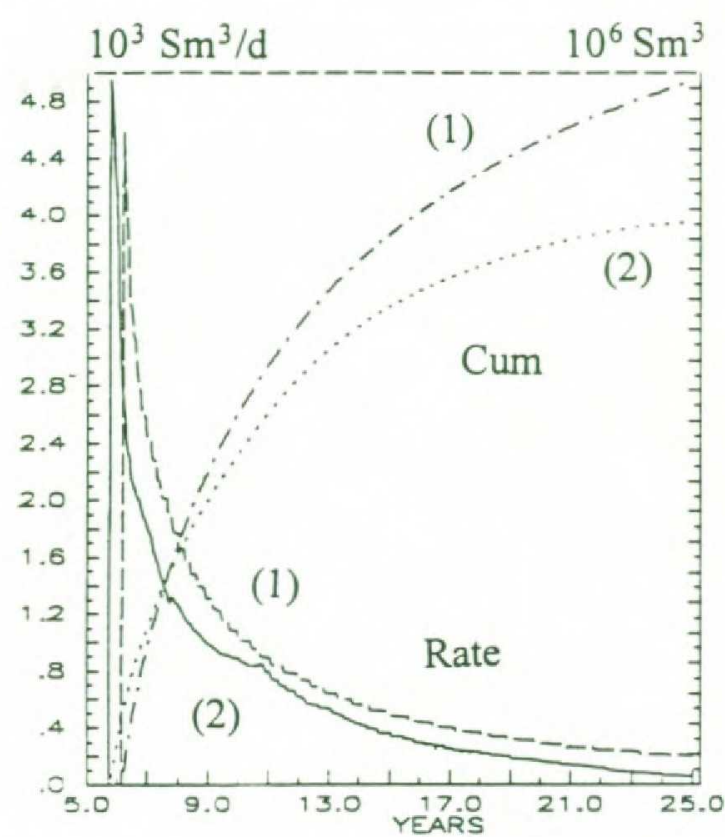

Fig. 5. Oil Production Profiles

(1) : Interior well

(2) : Flank well

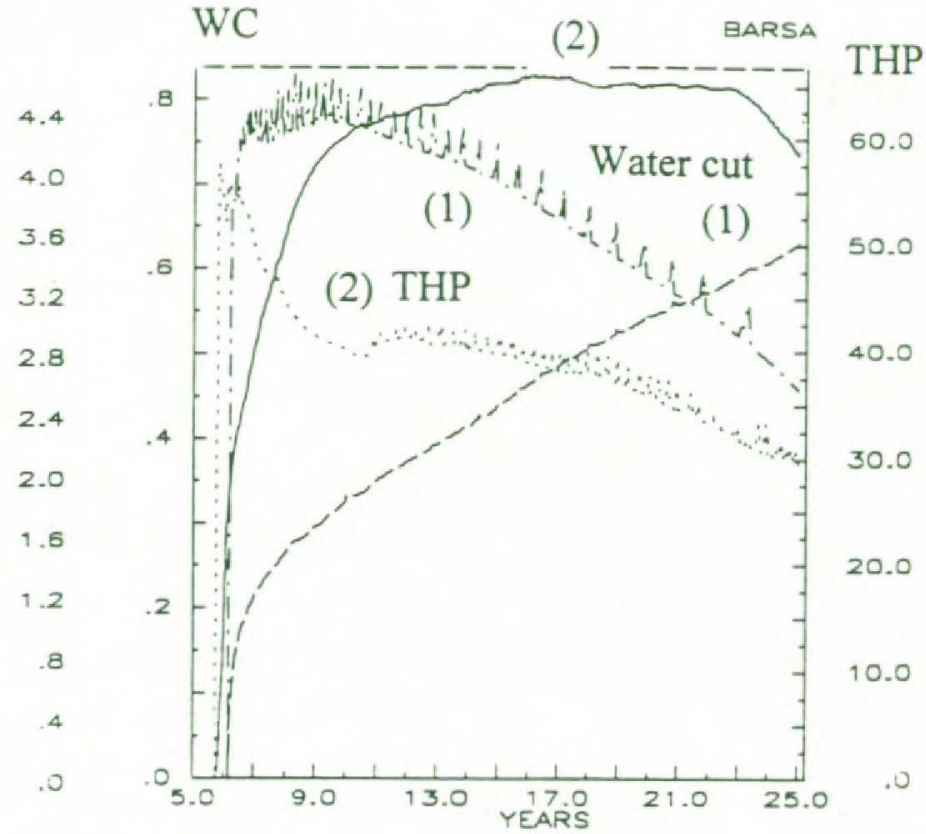

Fig. 6. Well Performance Plots
(1) : Interior well
(2) : Flank well

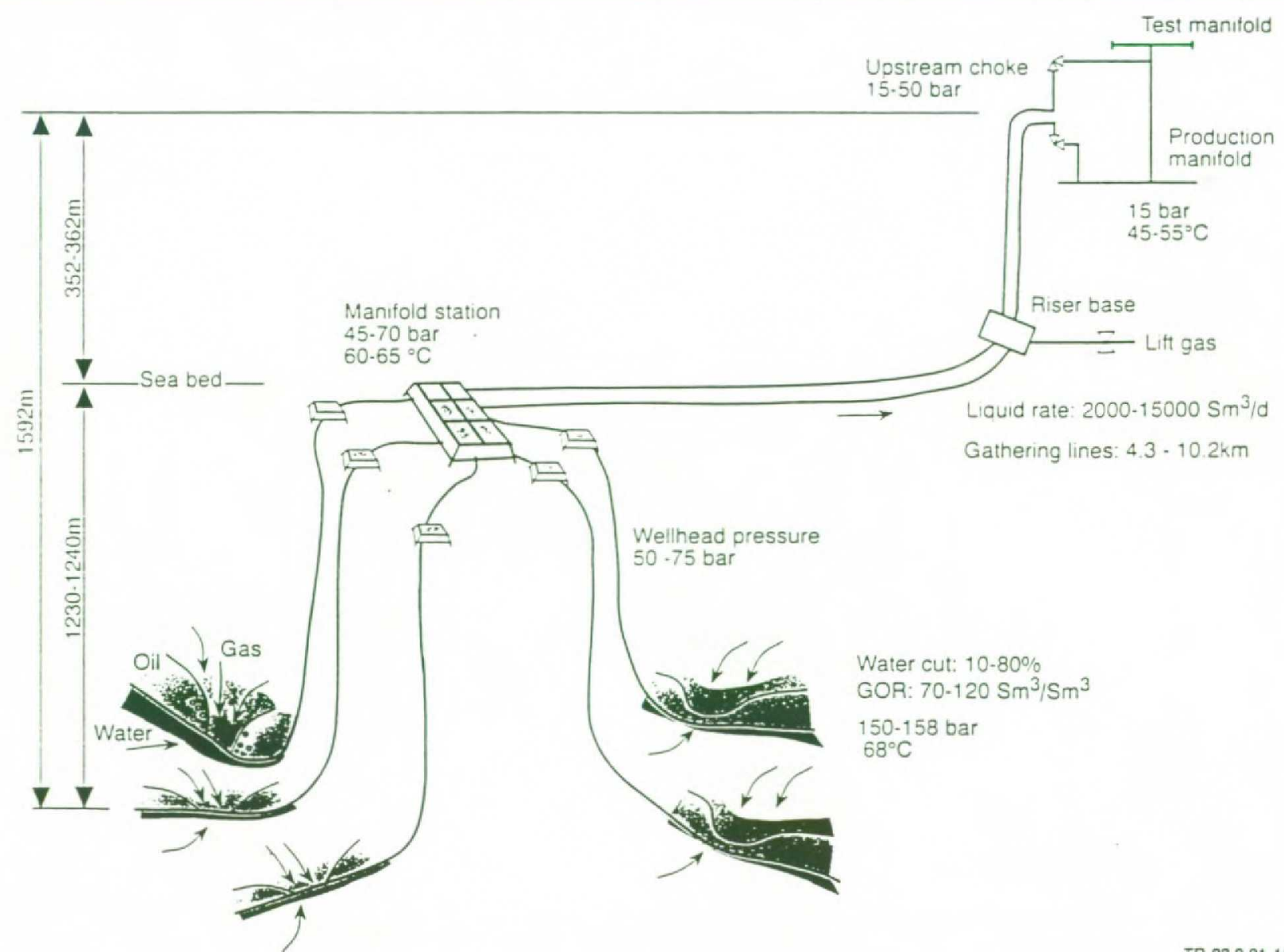




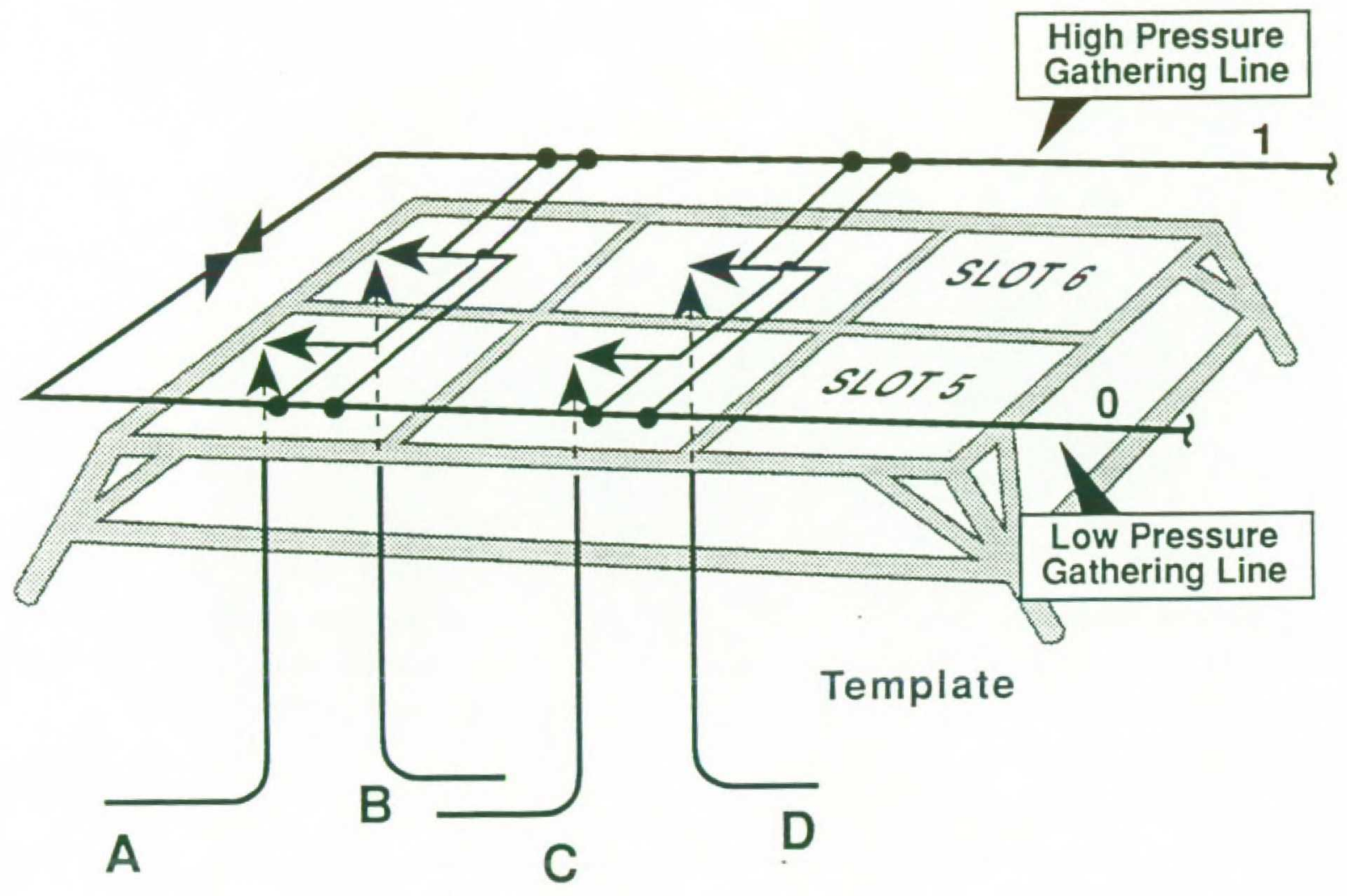

Fig. 8. A six-well manifold (6 slots)

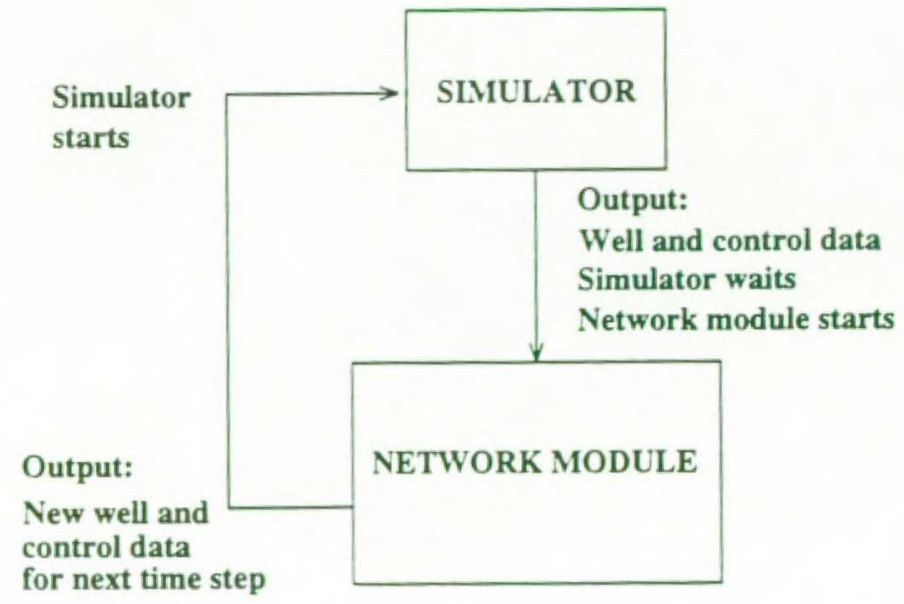

Fig. 9. Principle for simulator and network module interaction 
(SMYDAY)

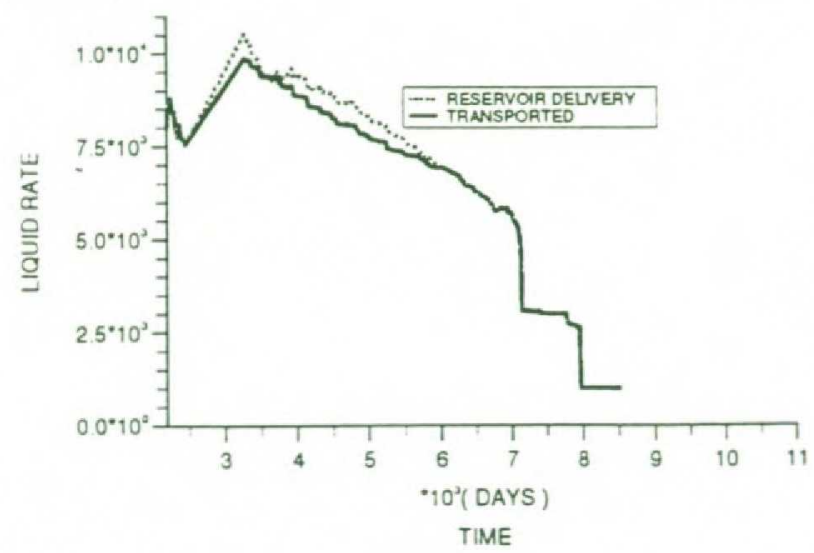

Fig. 10. Liquid reservoir delivery and amount possible to transport, without network module.
( SM3/DAY)

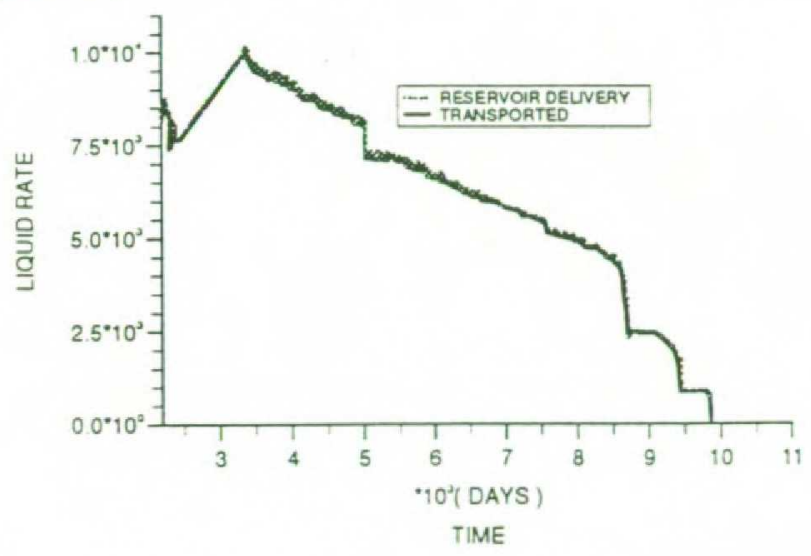

Fig. 11. Liquid reservoir delivery and amount possible to transport, with network module.

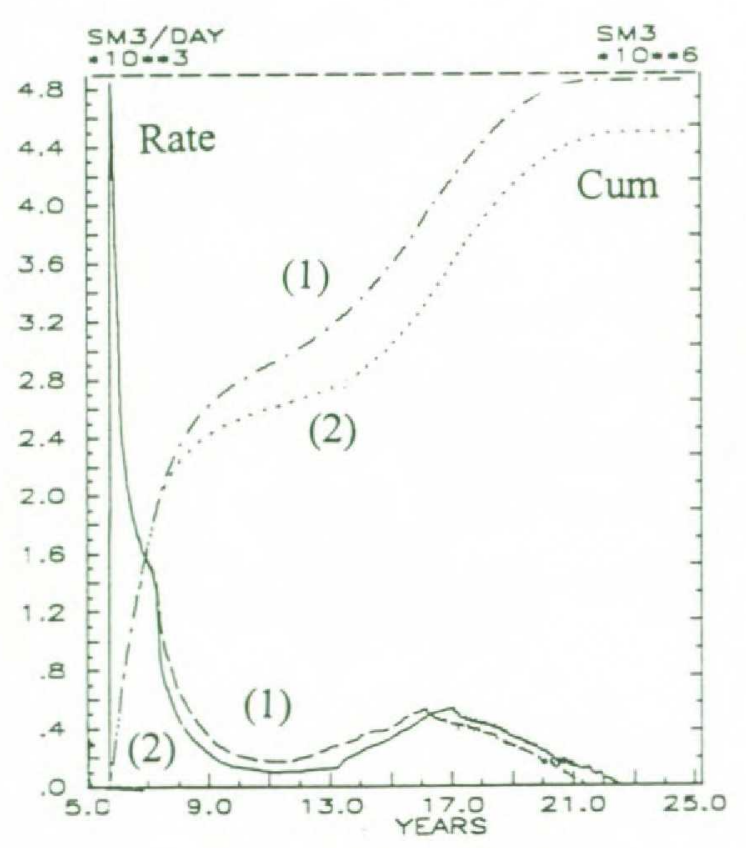

Fig. 12. Oil production for a high water cut well.

(1): Without network module (2): With network module

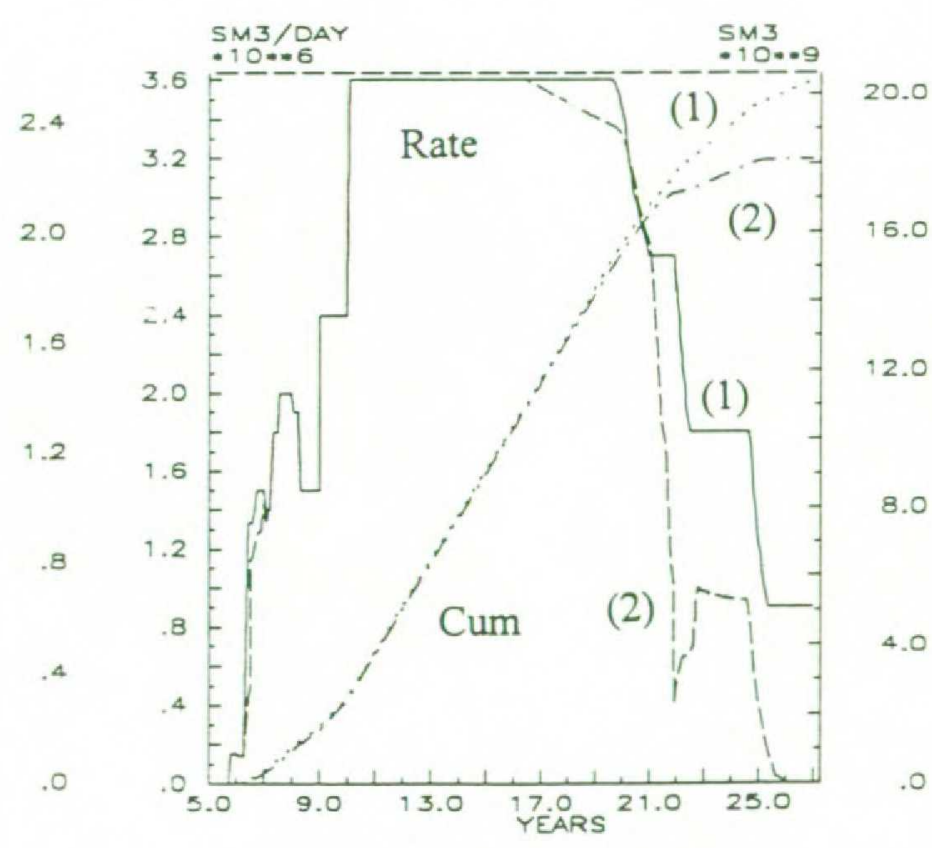

Fig. 13. Gas production for a TWGP-cluster.

(1): Without network module

(2): With network module 